Case Report

\title{
First Case of COVID-19-Associated Collapsing Glomerulopathy in Sub-Saharan Africa
}

\author{
Yannick M. Nlandu ${ }^{10},{ }^{1}$ Jean-Robert R. Makulo, ${ }^{1}$ Nestor M. Pakasa, ${ }^{2}$ Ernest K. Sumaili, ${ }^{1}$ \\ Clarisse N. Nkondi, ${ }^{1}$ Justine B. Bukabau, ${ }^{1}$ François K. Beya, ${ }^{2}$ Nazaire M. Nseka, ${ }^{1}$ \\ and François B. Lepira' ${ }^{1}$ \\ ${ }^{1}$ Kinshasa University Hospital, Nephrology Unit, Kinshasa, Democratic Republic of the Congo \\ ${ }^{2}$ Division of Uro-Nephropathology, Department of Pathology, Kinshasa, Democratic Republic of the Congo \\ Correspondence should be addressed to Yannick M. Nlandu; yannicknlandu@yahoo.fr
}

Received 8 July 2020; Revised 4 September 2020; Accepted 17 September 2020; Published 28 September 2020

Academic Editor: Raoul Bergner

Copyright (c) 2020 Yannick M. Nlandu et al. This is an open access article distributed under the Creative Commons Attribution License, which permits unrestricted use, distribution, and reproduction in any medium, provided the original work is properly cited.

\begin{abstract}
Although the lungs remain the main target of SARS-CoV-2, other organs, such as kidneys, can be affected, which has a negative impact on the outcomes of COVID-19 patients. Although previous studies of kidney disease in COVID-19 reported mainly SARS$\mathrm{CoV}$-2-induced tubular and interstitial injury, there is growing evidence coming out of Africa of glomerular involvement, especially collapsing glomerulopathy seen particularly in people of African descent. We report a case of collapsing glomerulopathy revealed by acute kidney injury and a new onset of full blown nephrotic syndrome in a black Congolese patient coinfected with COVID-19 and malaria.
\end{abstract}

\section{Introduction}

The COVID-19 pandemic has caused unprecedented health, social, and economic crises worldwide $[1,2]$. While the lungs are the organ primary target of SARS-CoV-2 and subsequent COVID-19, other organs, including kidneys, can be affected, and this is associated with increased mortality and morbidity [3, 4]. Previous autopsy reports from China and more recent reports from the USA have described mostly kidney tubular injury associated with SARS-CoV-2 [5, 6]. However, cumulating evidence from Europe and the USA yields collapsing glomerulopathy (CG), a variant of focal segmental glomerulosclerosis (FSGS) [7]. Interestingly, the patients reported in these early papers are of African descent, and the presence of two apolipoprotein L1 (APOL1) risk alleles likely contributes to the pathogenesis of the renal disease [7]. To date, there has been no similar report from continental Africa. We report the first COVID-19-associated CG from sub-Saharan Africa, in a Congolese patient infected with COVID-19, who presented with acute kidney injury (AKI) and de novo nephrotic syndrome.

\section{Case Presentation}

A 48-year-old African man presented to the Kinshasa University Hospital (KUH) for persistent fever since March 16,2020 , associated with dry cough, vomiting, myalgia, and generalized weakness. At home, he self-medicated with two antimalarial medications (artemether and lumefantrine) for three days. His symptoms persisted, and he visited a medical center on March 23, 2020. A blood smear demonstrated Plasmodium falciparum and was given intravenous Artesunate, another antimalarial drug, for five days combined with cefixime, a broad-spectrum, third generation cephalosporin.

Two weeks after his symptoms began, he experienced anuria and he visited the emergency unit of KUH on April 2, 2020. He stated that sixteen days previously he had been in contact with a person known to have COVID-19. His past 
TABLE 1: Summary of laboratory evaluations and relevant trends during hospitalization.

\begin{tabular}{|c|c|c|c|c|c|c|c|c|}
\hline Test & Reference & $\begin{array}{l}\text { March 16, } \\
2020\end{array}$ & $\begin{array}{l}\text { April 2, } \\
2020\end{array}$ & $\begin{array}{l}\text { April 15, } \\
2020\end{array}$ & $\begin{array}{l}\text { April 22, } \\
2020\end{array}$ & $\begin{array}{l}\text { April 29, } \\
2020\end{array}$ & $\begin{array}{c}\text { May 2, } \\
2020\end{array}$ & $\begin{array}{l}\text { May 7, } \\
2020\end{array}$ \\
\hline Blood urea $(\mathrm{mg} / \mathrm{dl})$ & $11.3-40.3$ & & 222.4 & 108.3 & 99.1 & 198.8 & 138 & 195.9 \\
\hline Serum creatinine $(\mathrm{mg} / \mathrm{dl})$ & $0.6-1.3$ & & 15.98 & 15.9 & 2 & 13 & 12 & 6.77 \\
\hline Potassium $(\mathrm{mmol} / \mathrm{l})$ & $3.0-5.0$ & & 5.2 & 4.7 & & 3.7 & & \\
\hline Sodium $(\mathrm{mmol} / \mathrm{l})$ & $135-145$ & & 135 & 135 & & 133 & & \\
\hline Bicarbonate (mmol/l) & $18-24$ & & 14.1 & & & 22 & & \\
\hline Ionized calcium (mmol/l) & $1.18-1.32$ & & 0.92 & 1.07 & & 0.72 & & \\
\hline Hemoglobin (g/dl) & $12.5-15$ & & 18.3 & & & 14.3 & 11.1 & 11.4 \\
\hline Hematocrit $(\%)$ & $36-45$ & & 50.1 & & & 42 & 33 & 31.9 \\
\hline $\begin{array}{l}\text { White blood cell count } \\
\left(\text { elements } / \mathrm{mm}^{3}\right)\end{array}$ & $4,000-10,000$ & & 14,630 & & & & & 7,830 \\
\hline Lymphocyte count (\%) & $20-40$ & & 17.1 & & & & & 9.5 \\
\hline Platelets (elements $/ \mathrm{mm}^{3}$ ) & $150,000-450,000$ & & 313,000 & & & & & 366,000 \\
\hline Albumin $(\mathrm{g} / \mathrm{dl})$ & $35-45$ & & & & & & 2.3 & \\
\hline Total cholesterol(mg/dl) & $<200$ & & & 22.06 & & & 384 & \\
\hline HDL cholesterol (mg/dl) & $>45$ & & & 840 & & & 51 & \\
\hline LDL cholesterol (mg/dl) & $<100$ & & & & & & 272 & \\
\hline Triglycerides $(\mathrm{mg} / \mathrm{dL})$ & $<150$ & & & & & & 307 & \\
\hline $\begin{array}{l}\text { Erythrocyte sedimentation } \\
\text { rate }(\mathrm{mm} / \mathrm{h})\end{array}$ & $10-20$ & & 85 & & & & & \\
\hline $\mathrm{CRP}(\mathrm{mg} / \mathrm{l})$ & $<6$ & $>16$ & & & & & $<6$ & \\
\hline
\end{tabular}

medical history was remarkable for diabetes mellitus type II and hypertension for the past three years. His medications included the oral antidiabetic drug repaglinide and the antihypertensive drug amlodipine. His family history was notable in that his father had chronic kidney disease. Laboratory tests six months prior to admission included a serum creatinine of $0.72 \mathrm{mg} / \mathrm{dL}$ and urinalysis that showed no proteinuria.

On hospital admission, he was noted to be dyspneic, with a respiratory rate of 23 breaths per minute. His blood pressure was $152 / 84 \mathrm{mmHg}$ and oxygen saturation was $93 \%$. A nasopharyngeal swab sample was positive for COVID-19 mRNA by reverse transcriptase-PCR (RT-PCR). Kidney function tests revealed severe kidney dysfunction, with increased plasma level of urea $(222 \mathrm{mg} / \mathrm{dL})$ and creatinine (15.9 mg/dL). A kidney ultrasound excluded an obstructive uropathy; kidney echogenicity, length $(13.2 \mathrm{~cm})$, and resistive index (0.8) were increased. In the setting of anuria, no urinalysis was performed. Initial laboratory assessment and selected trends are depicted in Table 1.

A diagnosis of COVID-19 was made and the patient received chloroquine, azithromycin, and vitamin $\mathrm{C}$, starting on day 1 , according to the national COVID-19 management protocol (unpublished data). COVID-19 RT-PCR testing and Plasmodium falciparum blood smear performed on days 14 and 21 after his hospital admission were negative.

Assessment of kidney function included anuria, metabolic acidosis, hyperkalemia, and stage 3 AKI according to Kidney Disease Improving Global Outcomes (KDIGO) criteria. On April 2, the patient started hemodialysis three sessions per week. After five dialysis sessions, the patient progressively recovered renal function, with diuresis reaching 4 liters/day and a fall in serum creatinine levels $(2 \mathrm{mg} / \mathrm{dL})$. The clinical diagnosis was acute tubular necrosis.
One week after recovery of kidney function (admission day 27), he developed full blown nephrotic syndrome (NS), characterized by heavy proteinuria $(18 \mathrm{~g} / \mathrm{d})$, hypoalbuminemia (serum albumin $2.3 \mathrm{~g} / \mathrm{dL}$ ), and dyslipidemia; microscopic urinalysis was normal. He experienced progressive increase in serum creatinine up to $13 \mathrm{mg} / \mathrm{dL}$. There were no episodes of hypotension, and the patient received no nephrotoxic drugs. A kidney ultrasound excluded renal vein thrombosis. Serologic analyses for hepatitis B, hepatitis C, cytomegalovirus, and HIV were negative. A percutaneous kidney biopsy was performed on hospital day 30 . The biopsy contained three cores, each of which contained with both renal cortex and medulla. They yielded a total of 17 glomeruli, none of which was globally sclerotic. All but one displayed segmental or global collapse, implosion of the glomerular capillary tuft, and enlargement of Bowman space (Figure 1).

Bowman space was occupied by hypertrophic and hyperplastic epithelial cells in 1-3 layers some of which showed cytoplasmic vacuolization and occasional protein droplets. Multiple early synechiae connecting glomeruli to Bowman capsule were seen. There was a severe tubular injury, with degenerative and regenerative changes. They included epithelial cell denudation loss and attenuation of the tubular brush border and cellular blebbing and mitoses. These changes in tubules were strongly Ki-67 positive, a molecular marker of cell proliferation (not shown) by immunohistochemistry.

Tubules showed microcystic dilatation and contained positive proteinaceous casts. Some proximal tubules also contained abundant PAS-positive resorption protein droplets. Tubulitis was not seen. The interstitium showed mild edema and patchy moderate fibrosis and patchy moderate to marked chronic inflammatory cell infiltrate. 


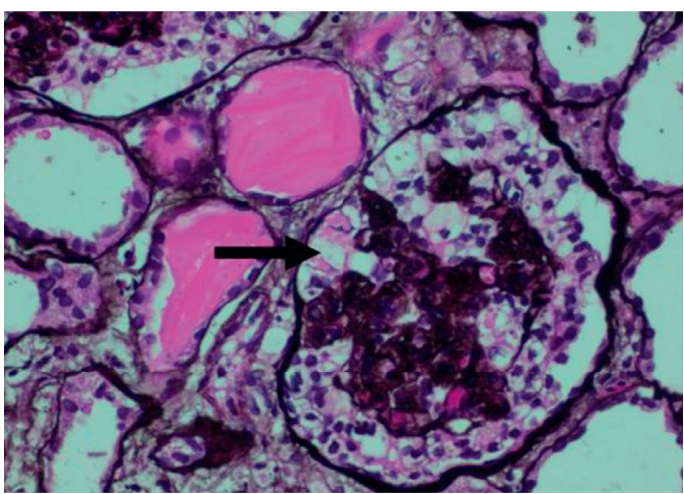

(a)

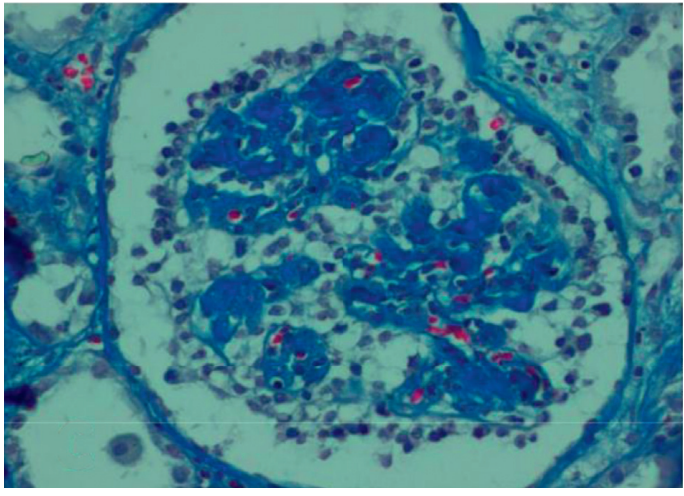

(c)

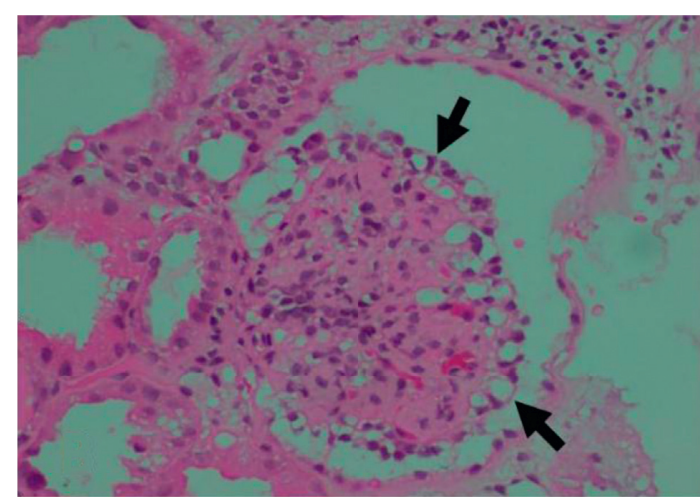

(b)

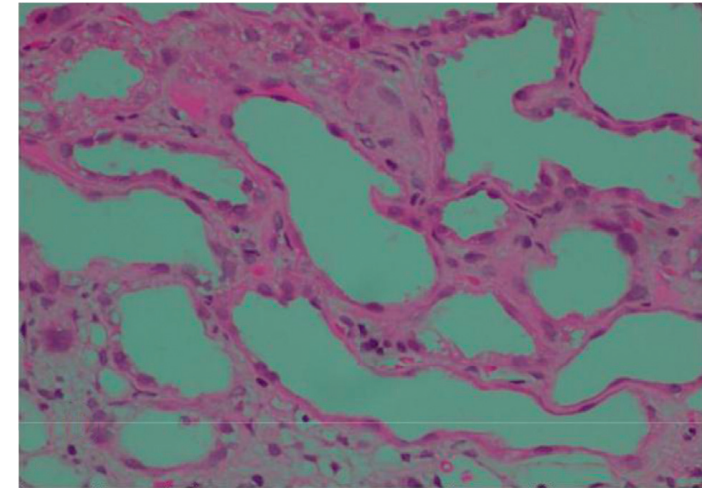

(d)

FIGURE 1: Kidney biopsy: representative light microscopy shows global collapse of the glomerular capillary loops accompanied by hyperplasia and hypertrophy of overlying glomerular epithelial cells $(\mathrm{a}-\mathrm{c})$ many of which contain scattered eosinophilic protein droplets $(\mathrm{a}$, arrow) and numerous intracytoplasmic vacuoles (b, arrows). a: Jones methenamine silver stain; b: H\&E stain; c: Masson's trichrome stain, $\times 400$. Acute tubular injury is manifest in many cortical tubules, accompanied by interstitial edema and patchy interstitial mononuclear inflammatory infiltrates (d: H\&E stain, $\times 400$ ).

The arteries and arterioles showed no conspicuous changes. The biopsy findings were interpreted as being consistent with the collapsing variant of FSGS based on Columbia classification of FSGS, also known as collapsing glomerulopathy (CG) [8].

Shortly after the kidney biopsy, the patient began producing urine. The patient received pulse therapy with methyl prednisolone intravenously, $500 \mathrm{mg}$ on days 1, 2, and 3, and cyclophosphamide intravenously, $500 \mathrm{mg}$ day 1 ; despite this therapy, proteinuria remains still heavy ( $4 \mathrm{~g}$ per day). Figure 2 shows changes in serum creatinine and proteinuria with time. Although kidney function does not return to normal, serum creatinine levels decreased to $5.0 \mathrm{mg} / \mathrm{dL}$ after two weeks.

\section{Discussion}

Prior studies on kidney disease, based on postmortem autopsy specimens in COVID-19 patients, showed acute tubular injury without glomerular abnormalities [5]. The authors linked these observations to the fact that angiotensin converting enzyme type 2 (ACE2) and transmembrane protein serine type 2 (TMPRSS2), proteins required for SARS-CoV-2 entry and replication in host cells, are prominently expressed in epithelial cells of proximal convoluted tubes [9]. However, recent reports from COVID19 patients demonstrated the glomerular injury mainly in the form of CG encountered particularly in people of African ancestry [7]. CG is an aggressive variant of FSGS exhibiting high rates of podocyte injury and depletion. Diseased podocytes exhibit a loss and gain of markers of differentiation and proliferation, respectively, and podocytes have been described to "transdifferentiate" toward a macrophagelike cell [10]. By light microscopy, CG is characterized by hyperplasic and hypertrophic visceral epithelial cells overlying segmentally or globally collapsed glomerular capillaries that are narrowed or obliterated by wrinkling and retraction of glomerular basement membranes [11]. The tubulointerstitial compartment often contains an infiltrate of mononuclear cells. Tubular epithelial cells typically display degenerative and regenerative changes and aberrant cellular proliferation and differentiation, leading to microcystic transformation. Tubular atrophy and interstitial fibrosis are common [11]. This histologic description corroborates the findings in the patient herein reported. Ancillary techniques such as electron microscopy (EM), immunofluorescence, in situ hybridization, and other sophisticated techniques have been used to identify pathogenic viral particles in biopsies from kidney structures in well-resourced settings, yielding so far no conclusive results besides podocyte changes related 


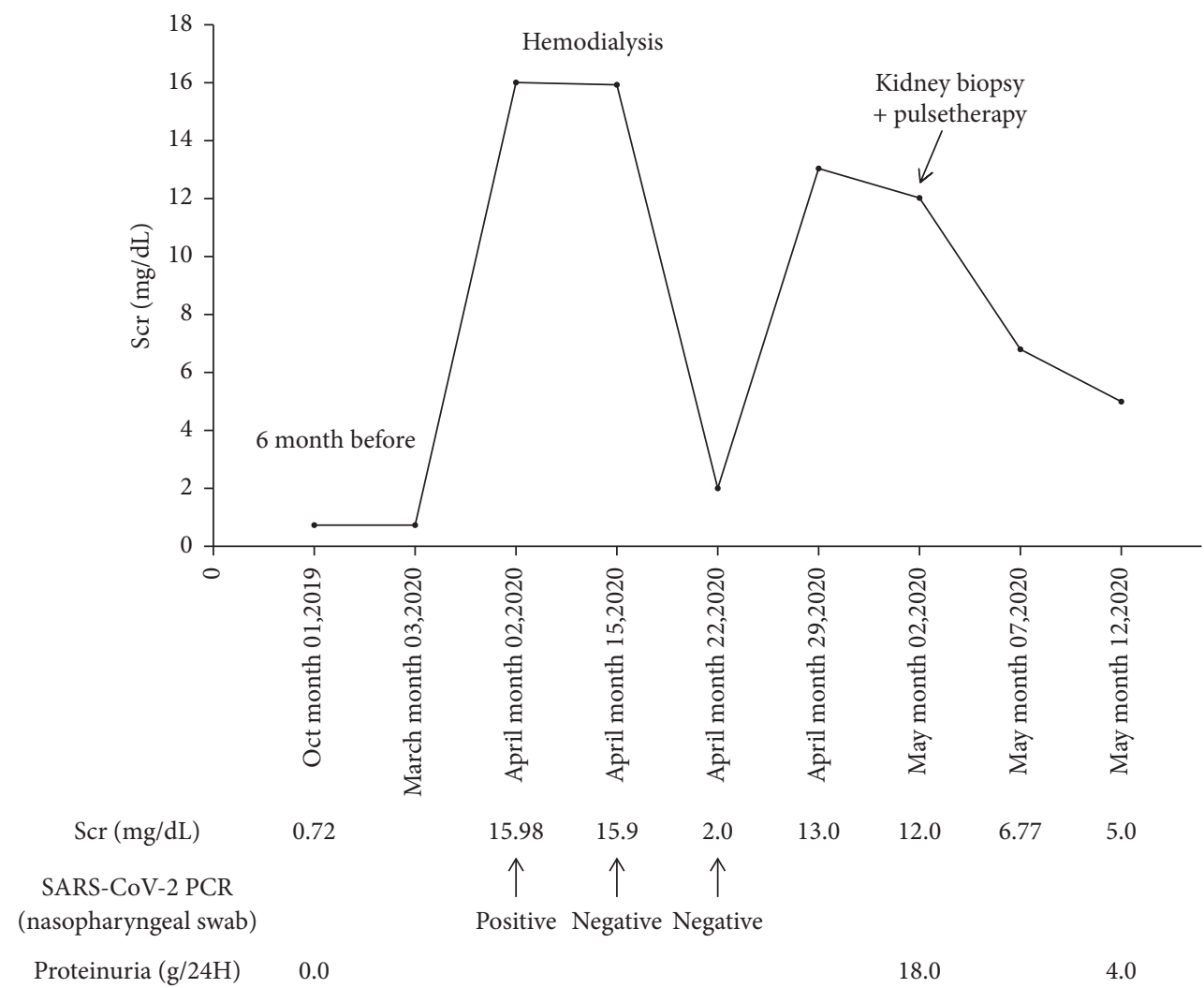

Figure 2: Changes in serum creatinine and proteinuria with time in a 48 -year-old African male admitted for acute kidney injury with COVID-19.

to proteinuria [12-14], although a recent EM report of a necropsy claims ultrastructural evidence for the presence of virus in podocytes [15].

In the present case report, AKI and NS with a bland microscopic urinalysis were the clinical expression CG. This clinical presentation of CG in the context of COVID-19 illness has been recently reported [11-17]. CG can be of idiopathic origin or most commonly secondary to autoimmune diseases, interferon therapy, and viral illnesses, including HIV, cytomegalovirus, and parvovirus B19 [16]. Our previous experience also reported CG associated with filariasis [17]. As many of these secondary causes were ruled out in the present patient, COVID-19 and coinfection with malaria were retained as potential causes of CG and ensuing NS and AKI. To date, less than 30 cases of CG have been described worldwide in the context of COVID-19, while AKI alone occurs in $1.3 \%$ to $36.4 \%$ [18]. Although rare, some cases of CG associated with malaria have also been described; indeed, malaria can be associated with hemolytic uremic syndrome or hemophagocytic syndrome $[19,20]$.

Kidney involvement in COVID-19 is now believed to originate from a double hit mechanism thought to rely upon the interaction of environmental factors, mainly SARS-CoV2 , altered host immune response, and genetic susceptibility. Recent data indicate that kidney injury in COVID-19 could be initiated by viral cytotoxicity or cytokine storm related to sepsis or other associated comorbidities [21]. Direct infection of kidney resident cells is enabled by the high expression of ACE2 and TMPRSS2 in epithelial cells of proximal convoluted tubes and podocytes [9]. The virus likely gains access to the kidney via the bloodstream [21].

Reports from Europe and the United States of America on CG in COVID-19 patients have indicated a high susceptibility of people of African descent compared to other people [7]. This high susceptibility of black people to CG has been reported to be linked to the presence of high kidney risk genotypes of $A P O L 1$ genes, well-known risk factors for the development of CG in HIV and non-HIV black patients [22]. Regardless of the associated disease, nearly $70 \%$ of these African-descent patients with CG are homozygous for APOL1 risk alleles [23]. In the Democratic Republic of the Congo, G1 APOL1 risk variants are frequent and are associated with hypertension-attributed nephropathy [24]. High-risk APOL1 genotype may mediate podocyte damage via up regulation of $A P O L 1$ through activation of a viral program in the podocyte, leading to dysregulated endosomal trafficking and autophagic flux, resulting in podocyte depletion and glomerular scarring [11].

In conclusion, this first report from African continent confirms that collapsing glomerulopathy now referred to as collapsing-associated nephropathy (COVAN) represents an emerging entity in the context of COVID-19 pandemic, particularly involving individual with sub-Saharan African ancestry.

\section{Consent}

Informed consent was obtained from the patient. 


\section{Conflicts of Interest}

The authors declare that they have no conflicts of interest.

\section{Acknowledgments}

This case benefited from a second opinion by Dr. Vivette d'Agati MD, Columbia University, College of Physicians and Surgeons, New York, USA. The authors gratefully thank the staff of the Nephrology Unit and the histotechnologists of the Pathology Department, Kinshasa University Hospital, for their commitment to always provide the utmost care to our patients. The authors also thank Dr. Jeffrey Kopp MD (National Institute of Health, Bethesda, USA) who provided editorial assistance.

\section{References}

[1] World Health Organization, Pneumonia of Unknown Cause-China, World Health Organization, Geneva, Switzerland, 2020, https://www.who.int/csr/don/05-january2020-pneumonia-of-unkown-cause-china/en/.

[2] M. Nicola, Z. Alsafi, C. Sohrabi et al., "The socio-economic implications of the coronavirus pandemic (COVID-19): a review," International Journal of Surgery, vol. 78, pp. 185-193, 2020.

[3] F. Zhou, T. Yu, R. Du et al., "Clinical course and risk factors for mortality of adult inpatients with COVID-19 in Wuhan, China: a retrospective cohort study," The Lancet, vol. 395, pp. 1054-1062, Article ID 10229, 2020.

[4] Y. Cheng, R. Luo, K. Wang et al., "Kidney disease is associated with in-hospital death of patients with COVID-19," Kidney International, vol. 97, no. 5, pp. 829-838, 2020.

[5] H. Su, M. Yang, C. Wan et al., "Renal histopathological analysis of 26 postmortem findings of patients with COVID19 in China," Kidney International, vol. 98, no. 1, pp. 219-227, 2020.

[6] M. E. Sise, M. V. Baggett, J.-A. O. Shepard, J. S. Stevens, and E. P. Rhee, "Case 17-2020: a 68-year-old man with covid-19 and acute kidney injury," New England Journal of Medicine, vol. 382, no. 22, pp. 2147-2156, 2020.

[7] S. H. Nasr and J. B. Kopp, "COVID-19-associated collapsing glomerulopathy: an emerging entity," Kidney International Reports, vol. 5, no. 6, pp. 759-761, 2020.

[8] M. Albaqumi and L. Barisoni, "Current views on collapsing glomerulopathy," Journal of the American Society of $\mathrm{Ne}$ phrology, vol. 19, no. 7, pp. 1276-1281, 2008.

[9] S. Mizuiri and Y. Ohashi, "ACE and ACE2 in kidney disease," World Journal of Nephrology, vol. 4, no. 1, pp. 74-82, 2015.

[10] J. A. Schwimmer, G. S. Markowitz, A. Valeri, and G. B. Appel, "Collapsing glomerulopathy," Seminars in Nephrology, vol. 23, no. 2, pp. 209-218, 2003.

[11] Y. Peleg, S. Kudose, V D’Agati et al., “Acute kidney injury due to collapsing glomerulopathy following COVID-19 infection," Kidney International Reports, vol. 5, no. 6, pp. 940-945, 2020.

[12] S. Kudose, I. Batal, D. Santoriello et al., "Kidney biopsy findings in patients with COVID-19," Journal of the American Society of Nephrology, vol. 31, no. 9, pp. 1959-1968, 2020.

[13] H. Wu, C. P. Larsen, C. F. Hernandez-Arroyo et al., "aki and collapsing glomerulopathy associated with COVID-19 and apoll high-risk genotype," Journal of the American Society of Nephrology, vol. 31, no. 8, pp. 1688-1695, 2020.
[14] A. Couturier, S. Ferlicot, K. Chevalier et al., "Indirect effects of severe acute respiratory syndrome coronavirus 2 on the kidney in coronavirus disease patients," Clinical Kidney Journal, vol. 13, no. 3, pp. 347-353, 2020.

[15] M. Abbate, D. Rottoli, and A. Gianatti, "COVID-19 attacks the kidney: ultrastructural evidence for the presence of virus in the glomerular epithelium," Nephron, vol. 144, no. 7, pp. 341-342, 2020.

[16] L. Nicholas Cossey, C. P. Larsen, and H. Liapis, "Collapsing glomerulopathy: a 30-year perspective and single, large center experience," Clinical Kidney Journal, vol. 10, no. 4, pp. 443-449, 2017.

[17] N. M. Pakasa, N. M. Nseka, and L. M. Nyimi, "Secondary collapsing glomerulopathy associated with loa loa filariasis," American Journal of Kidney Diseases, vol. 30, no. 6, pp. 836-839, 1997.

[18] X. Yang, Y. Jin, R. Li, Z. Zhang, R. Sun, and D. Chen, "Prevalence and impact of acute renal impairment on COVID-19: a systematic review and meta-analysis," Critical Care, vol. 24, no. 1, 2020.

[19] V. B. Kute, H. L. Trivedi, A. V. Vanikar, P. R. Shah, M. R. Gumber, and K. V. Kanodia, "Collapsing glomerulopathy and hemolytic uremic syndrome associated with falciparum malaria: completely reversible acute kidney injury," Journal of Parasitic Diseases, vol. 37, no. 2, pp. 286-290, 2013.

[20] A. Niang, S. E. Niang, E. H. F. Ka, M. M. Ka, and B. Diouf, "Collapsing glomerulopathy and haemophagocytic syndrome related to malaria: a case report," Nephrology Dialysis Transplantation, vol. 23, no. 10, pp. 3359-3361, 2008.

[21] X.-W. Pan, D. Xu, H. Zhang, W. Zhou, L.-H. Wang, and X.-G. Cui, "Identification of a potential mechanism of acute kidney injury during the COVID-19 outbreak: a study based on single-cell transcriptome analysis," Intensive Care Medicine, vol. 46, no. 6, pp. 1114-1116, 2020.

[22] S. Kissling, S. Rotman, C. Gerber et al., "Collapsing glomerulopathy in a COVID-19 patient," Kidney International, vol. 98 , no. 1, pp. 228-231, 2020.

[23] C. P. Larsen, T. D. Bourne, J. D. Wilson, O. Saqqa, and M. D. A. Sharshir, "Collapsing glomerulopathy in a patient with COVID-19," Kidney International Reports, vol. 5, no. 6, p. 935, 2020.

[24] E. K. Sumaili, R. Shemer, E. Kruzel-Davila et al., "G1 is the major APOL1 risk allele for hypertension-attributed nephropathy in Central Africa," Clinical Kidney Journal, vol. 12, no. 2, pp. 188-195, 2018. 